\title{
Late Holocene vegetation dynamics and deforestation in Rano Aroi: Implications for Easter Island's ecological and cultural history
}

\author{
Valentí Rull $^{\mathrm{a}^{*}}$, Núria Cañellas-Boltàa, Olga Margalef ${ }^{\mathrm{b}}$, Alberto Sáez ${ }^{\mathrm{c}}$, Sergi Pla-Rabes ${ }^{\mathrm{b}}$ \\ \& Santiago Giralt ${ }^{\mathrm{a}}$ \\ ${ }^{a}$ Institute of Earth Sciences Jaume Almera (ICTJA-CSIC), Lluís Solé i Sabarís s/n, \\ 08028 Barcelona, Spain \\ ${ }^{\mathrm{b}}$ Ecological Research Center and Forestry Applications (CREAF), Autonomous \\ University of Barcelona, Campus Bellaterra, Cerdanyola del Vallès, 08193 Barcelona, \\ Spain \\ ${ }^{\mathrm{C}}$ Department of Stratigraphy, Paleontology and Marine Geosicences, Universitat de \\ Barcelona. Martí i Franqués s/n, 08028 Barcelona, Spain
}

*Corresponding author. E-mail: vrull@ictja.csic.es

\begin{abstract}
Easter Island (Rapa Nui) has been considered an example of how societies can cause their own destruction through the overexploitation of natural resources. The flagship of this ecocidal paradigm is the supposed abrupt, island-wide deforestation that occurred about one millennium ago, a few centuries after the arrival of Polynesian settlers to the island. Other hypotheses attribute the forest demise to different causes such as fruit consumption by rats or aridity but the occurrence of an abrupt, island-wide deforestation during the last millennium has become paradigmatic in Rapa Nui. We argue that such a view can be questioned, as it is based on the palynological study of incomplete records, owing to the existence of major sedimentary gaps. Here, we present a multiproxy (pollen, charcoal and geochemistry) study of the Aroi core, the first gap-free sedimentary sequence of the last millennia obtained to date in the island. Our results show changing vegetation patterns under the action of either climatic or anthropogenic drivers, or both, depending on the time interval considered. Palm forests were present in Aroi until the 16th century, when deforestation started, coinciding with fire exacerbation likely of human origin and a dry climate. This is the latest deforestation event recorded so far in the island and took place roughly a century before European contact. In comparison to other Easter Island records, this record shows that deforestation was neither simultaneous nor proceeded at the same pace over the whole island. These findings suggest that Easter Island's deforestation was a heterogeneous process in space and time, and highlights the relevance of local catchment traits in the island's environmental and land management history.
\end{abstract}

\section{Introduction}

Easter Island (Rapa Nui in indigenous language) is one of the most remote and enigmatic places on Earth. It is famous for a mysterious extinct culture that is manifested as anthropomorphic stone statues called moais. The disappearance of this megalithic culture has been associated with a presumed "ecocidal” socioecological collapse triggered by the over-exploitation of natural resources, a scenario that has been 
presented as a microcosmic model of how humans can destroy their own habitat and lead themselves to societal breakdown (Flenley and Bahn, 2003; Diamond, 2005). This view was based on the first palynological studies carried out by Flenley and King (1984) and Flenley et al. (1991) and has received extensive media coverage influencing public opinion and also the theoretical study of the evolution of civilisations. According to this view, the initial human occupation of Easter Island occurred relatively recently, likely between AD 800 and 1000, and the settlers proceeded from western Polynesia (Vargas et al., 2006) (Fi. 1). The presumed socio-ecological collapse would have occurred shortly after, between AD 1000 and 1200 (Mann et al., 2008). Europeans arrived to the island in 1722 (Flenley and Bahn, 2003). Another view proposes a similar collapse but different causes. According to Hunt (2006, 2007), the deforestation would have been caused by the Polynesian rat Rattus exulans, carried by humans to the island, which ate the fruit thus preventingforest regeneration. The same authors suggest that the cultural

\section{Study site}

Easter Island (Fig. 1) is located in the eastern Pacific Ocean (27o 0701600 S, 109o 21' 59 ” W) at about $3700 \mathrm{~km}$ of the Chilean coast and $2030 \mathrm{~km}$ from the nearest oceanic island (Pitcairn). The island originated by the fusion of three volcanic cones (Maunga Terevaka, Kao and Poike), which formed a roughly triangular land mass of nearly 164 km2 (Fig. 1). In addition to these major volcanoes, the island is spiked by around 70 other minor satellite cones. The island is dominated by the summit of the Terevaka volcano (511 m elevation), which has steep slopes at the north and more gentle slopes in the other directions, where most inhabited sites of the island are located. The climate of Easter Island is subtropical, with an average annual temperature of $21 \mathrm{oC}$ and a range of average monthly temperatures between 18 oC in August and 24 oCin January (Mann et al., 2008). The total annual precipitation is highly variable, ranging between 500 and $1800 \mathrm{~mm}$ (average $1130 \mathrm{~mm}$ ); the maximum rainfall occurs from April to June, and the driest month is October with $70 \mathrm{~mm}$ (Azizi and Flenley, 2008). The island is covered by meadows (90\%), forests (5\%), shrublands (4\%), and pioneer and urban vegetation (1\%) (Etienne et al., 1982). The meadows are dominated by grasses, mainly Sporobolus indicus and Paspalum scrobiculatum, with Axonopus paschalis as local dominant in the highest sectors of the Maunga Terevaka. The more common forests are recent plantations of Eucalyptus spp. (Myrtaceae) and Dodonaea viscosa (Sapindaceae), both introduced, and the native Thespesia populnea (Malvaceae). Shrublands are largely dominated by the invader Psidium guajava (Myrtaceae), also introduced. Inside the major craters, the only places of the island with permanent fresh water, aquatic vegetation is dominated by Scirpus californicus (Cyperaceae) and Polygonum acuminatum (Polygonaceae).

Rano Aroi is a mire of $\sim 150$ m diameter situated at 430 m elevation and located in an ancient Pleistocene volcano crater near the highest summit of the island (Fig. 1). Water level is controlled by groundwater inputs subjected to the influence of seasonal variations in precipitation, and human extraction, through the construction of an artificial outlet in the 1960s (Herrera and Custodio, 2008). The vegetation of the mire is characterized by Scirpus californicus, P. acuminatum and the ferns Asplenium polydon, Vittaria elongata and Cyclosorus interruptus; the surrounding area is covered by grasslands and a small Eucalyptus forest planted during the 1960s (Zizka, 1991). 


\section{Methods}

\subsection{Coring}

The core studied (ARO 08-02) was obtained in 2008 with a Russian corer of $5.5 \mathrm{~cm}$ diameter and a 50-cm long chamber. The core was retrieved after 8 drives for a total depth of $400 \mathrm{~cm}$. The upper $75 \mathrm{~cm}$ were water, hence, the total peat depth was $325 \mathrm{~cm}$. The cores were sealed, transported to the laboratory and stored at $4 \mathrm{oC}$. This paper concentrates on the uppermost $\sim 2 \mathrm{~m}$ of the peat section representing approximately the last three millennia.

\subsection{Dating}

Samples for AMS radiocarbon dating consisted of pollen extracts (Vandergoes and Prior, 2003). Dating was performed at BETA Analytic (USA) and the Poznan Radiocarbon Laboratory (Poland). The obtained ages were calibrated with CALIB 7.0 using the SHcal13 curve (Hogg et al., 2013). The age-depth model was constructed with CLAM (Blaauw, 2010; Blaauw and Heegaard, 2012). Considering the statistical errors of this age-depth model, dates are expressed as the mid-point estimation (median) plus/minus the $95 \%$ confidence interval, using the BC/AD scale. Dates from others papers used in the discussion section are expressed in the same format as their original references.

\subsection{Geochemistry}

The core was sampled every $5 \mathrm{~cm}$ to determine total carbon, total nitrogen and their stable isotopes. Samples were dried at 60 oC for two days, frozen with liquid nitrogen and ground in a ring mill.

$2.5 \mathrm{mg}$ of the powdered sample was weighed using a microbalance and packed in tin (Sn) capsules. The concentration and isotopic measurements were carried out using a Finnigan Delta Plus EAeCFeIRMS spectrometer.

\subsection{Palynology and charcoal analysis}

Samples for palynological analysis consisted of $2 \mathrm{e} 4 \mathrm{~g}$ of wet sediment. Chemical processing included $\mathrm{KOH}, \mathrm{HCl}$ and $\mathrm{HF}$ digestions, and acetolysis, after spiking with Lycopodium tablets (Bennett and Willis, 2001). Pollen counting was conducted until a minimum of 200 pollen grains and the saturation of taxa diversity (Rull, 1987). The pollen sum used to calculate percentages consisted of only pollen grains, excluding those corresponding to aquatic and semi-aquatic plants. Diagrams were plotted with psimpoll 4.27 and zonation was performed using optimal splitting by information content (Bennett, 1996). Charcoal counts were carried out in the same samples used for pollen analysis. Charcoal particles below $5 \mathrm{~mm}$ of maximum length were not considered as a number of them could be the result of the breakage of larger particles.

\section{Results and interpretation}

\subsection{Chronology}

The establishment of a sound age-depth model was a critical step in this research. Table 1 shows the details of radiocarbon dating and the resulting age model is depicted in Fig. 
2. The model shows a continuous sedimentary trend with no gaps and age inversions. According to this model, the analyzed core contains 2600 years, ranging between approximately $750 \mathrm{BC}$ and $\mathrm{AD} 1810$. The average accumulation rate is $0.7 \mathrm{~mm} \mathrm{y}-1$.

\subsection{Vegetation dynamics and fire}

The pollen diagram is dominated by palms (Arecaceae), com $\neg$ posites (Asteraceae) and grasses (Poaceae) (Fig. 3). There is a con $\neg$ spicuous difference between the lower part of the diagram, where most pollen types remain at similar percentages, and the upper $\neg$ most section, where all types exhibit fluctuations. To facilitate interpretation, the diagram was subdivided into four phases.

Phase I (750 $\pm 130 \mathrm{BC}$ to AD $1250 \pm 60)$ shows a remarkable constancy in pollen assemblages and, therefore, in vegetation pat $\neg$ terns through time. The dominant pollen types are palms and composites, both with values of approximately $20 \mathrm{e} 40 \%$, suggesting the occurrence of a palm woodland with compositae shrubs in the understory. Grasses also showed constant and persistent values (50e80\%) suggesting that grasslands were important, likely dominant, regionally. Plants typical of the present-day local mire vegetation (Cyperaceae, Polygonum and ferns) were almost completely absent. Within this uniformity, a recurrent pattern emerges in the form of two sequences of palmAsteraceae-grass peaks likely representing processes of landscape opening from palmdominated to grassland-dominated landscapes. These se $\neg$ quences lasted several centuries each and occurred between ca. $300 \pm 80 \mathrm{BC}$ and AD $50 \pm 70$ (LO1) and between ca. AD $600 \pm 65$ and AD $1100 \pm 60$ (LO2), respectively.

Phase II (AD $1250 \pm 60$ to AD $1520 \pm 85$ ) began with a con $\neg$ spicuous increase in Sophora (up to 20\%), suggesting that this shrub started to be important in the understory of the palm woodland to the detriment of Asteraceae, which underwent a significant decline. Sophora peaked around AD $1340 \pm 70$ and disappeared at AD $1490 \pm 80$, coinciding with a significant increase in palms. The pollen assemblage of this phase is suggestive of a progressive densification of palm woodlands to more closed forests at the expense of the understory shrubs, a situation that reached a maximum at AD $1520 \pm$ 85. The elements of the local mire vege $\neg$ tation also underwent a remarkable increase coinciding with woodland densification.

Phase III (AD $1520 \pm 85$ to AD $1620 \pm 110$ ) was characterized by the abrupt decline and further disappearance of palm and Asteraceae pollen, suggesting rapid deforestation coinciding with the equally abrupt decline of mire vegetation and the maximum amount of grasses (90\%), which is interpreted as the establishment of present landscapes dominated by grasslands and devoid of the former palm forests. The palynological expression of this deforestation (LO3) is similar to the former phases of landscape opening (LO1 and LO2) but is significantly faster. It is noteworthy that the intermediate Aster $\neg$ aceae peak is lacking, suggesting the synchronous elimination of the canopy trees and the understory shrubs. The coincidence of this forest demise with a conspicuous increase in charcoal suggests that fire likely played a leading role in deforestation. Present-day landscapes, totally dominated by grasslands without any representatives of the former woodland vegetation, were established during phase IV (AD $1620 \pm 110$ to AD $1810 \pm 130$ ). A peak in fire incidence was recorded at AD $1660 \pm 130$, followed by a rapid decline until the end of the diagram. 


\subsection{Climatic/environmental trends}

The more significant variations in geochemical proxies were two shifts coinciding with the pollen sequences of landscape opening LO1 and LO2. In both sequences, a consistent pattern of $\mathrm{C} / \mathrm{N}$ decline, related mainly to an increase in nitrogen, coupled with increases in d15Nand d13C, is manifest (Fig. 4). A decline in the $\mathrm{C} / \mathrm{N}$ ratio and an increase in $\mathrm{d} 15 \mathrm{~N}$ are compatible with lower water levels, stagnation, and eventually drying, along with changes in the peat-forming vegetation. In these anoxic conditions, when the nitrogen supply is high, denitrification processes are favored and denitrifying bacteria select the more labile $14 \mathrm{~N}$, which is lost via degasification, thus causing $15 \mathrm{~N}$ enrichment (Houlton and Bai, 2009; McLauchlan et al., 2013). The increase in d13C could be due, in part, to the general in-crease of C4 grasses (-16 to $-10 \%$ ) to the detriment of palms and other C3 plants and algae (-33 to -24\%o)(O'Leary, 1988). Patterns of variation in pollen and geochemistry are consistent with dry climates during LO1 and LO2, as manifested in low water levels and the establishment of open vegetation at the expense of palm woodlands. Wetter climates would have returned during Phase II, as suggested by d13C values around -25\%, indicating the local dominance of C3 plants, including palms, ferns and aquatic species, and d15Nvalues close to zero, which is compatible with increased nitrogen fixation by cyanobacteria due to higher water levels. During Phase IV, geochemical proxies show a trend similar to the lower half of LO1 and LO2, suggesting the initiation of a third shift to a drier climate.

\section{Discussion and conclusions}

5.1. Vegetation and climate prior to polynesian settlement $(750 \pm 130 \mathrm{BC}$ to AD $1250 \pm$ 60)

The constancy of vegetation documented in Phase I coincides with the results of previous palynological analyses, which extended this constancy to approximately 30,000 years BP (Flenley and King, for this and interpret our pollen assemblages as indicative of a palm 1984; Flenley et al., 1991; Azizi and Flenley, 2008). The main difwoodland with a shrubby understory dominated by compositae, a ference is that in these previous works, Rano Aroi was considered to situation that is common in other Pacific islands (Vargas et al., hold ecotonal vegetation corresponding to the upper forest 2011). According to regional paleoclimatic reconstructions of boundary. We believe that we do not have any conclusive evidence Eastern Polynesia (Nunn, 2007), climates during Phase I were warm and dry, characterized by severe droughts, reduced storminess and low interannual variability (Fig. 5). Based on vegetation shifts, LO1 and LO2 are strong candidates for drier intervals, and this interpretation is supported by biogeochemical proxies. Sequence LO1 occurred before the Preclassic Maya Collapse of Central America, a period when the Pacific sea level was 1e2 m higher than the present. Since that time, sea level has fallen gradually, but it remained higher than at present until the end of Phase I. Sequence LO2 was coeval with the Classic Maya Collapse ( AD 900) attributed to a number of prolonged droughts that contributed to the final demise of this civilization (Haugh et al., 2003). In the Pacific islands, the LO2 period was characterized by sea levels higher than today and increased food production thanks to the development of irrigation practices and terracing (Nunn, 2007). 
5.2. Post-settlement, climatic crisis and coastal abandonment (AD $1250 \pm 60$ to AD $1620 \pm 110)$

According to archaeological evidence, Polynesian colonizers arrived at Easter Island at the end of Phase I or the beginning of Phase II, although the dates of arrival range from AD 800 to AD 1300, depending on the authors (Flenley and Bahn, 2003; Hunt and Lipo, 2006; Vargas et al., 2006; Wilmshurst et al., 2011). This was a period of intensified long-distance navigation and new settlements, especially in the eastern Pacific, where many islands and archi $\neg$ pelagos were likely colonized by Polynesians during this time (Fig. 5) (Nunn, 2007). At Easter Island, the end of Phase I was a time of societal prosperity and open coastal settlement, known as Ahu Moai, when the construction of the emblematic moais reached its maximum (Flenley and Bahn, 2003). However, Phase II witnessed a different scenario. Our interpretation of wetter climates during Phase II also coincides with regional trends. The onset of this phase was coeval with a regional lowstand phase and a change in the climate to a cooler and wetter climate with increased storminess due to ENSO intensification, which has been described as the "1300 event" (Nunn, 2007). During the second part of Phase II, the onset of palm forest densification at Aroi coincided with another regional climate shift to the cold and dry Little Ice Age (LIA) climate. The sea level remained lower than today and inter-island navigation was significantly reduced. Archaeological reconstructions of Easter Island show that coastal settlements began to be abandoned and replaced by inland and upland habitats (Nunn, 2007). Societal conflicts started to be frequent, but the Ahu moai period continued during the first part of Phase II.

\subsection{Deforestation and European contact (AD $1620 \pm 110$ to AD $1810 \pm 130$ )}

The onset of deforestation (Phase III) coincided with the beginning of the Huri moai phase, characterized by moai toppling, societal conflict and cave settlement. The significant role of fire in deforestation suggests that humans could have been involved. Drier climates could have facilitated the initiation and spread of fire by increasing the ignitability and vegetation flammability, but climatic dryness alone is unlikely to have been the cause for deforestation, as former dry shifts (LO1 and LO2) were not sufficient to initiate fires and/or remove forests. This is the most recent well $\neg$ dated deforestation event recorded so far at Easter Island, and it started between AD 1435 and AD 1605 (considering the 95\% confidence interval of the age-depth model), more than a century before European contact (AD 1722). Therefore, if humans were involved in deforestation by fire, Rapanuis are the most likely candidates, as Europeans had not yet arrived at the island. It is noteworthy that the Aroi forests were in place six centuries after the dates proposed by the ecocidal theory for island deforestation, which agrees with the predictions of the genocidal view (Rainbird, 2002; Peiser, 2005). However, as discussed below, the Aroi deforestation took place well before European contact. Using the charcoal record as a proxy for human activity in the Aroi catchment, we note that intense landscape disturbance did not began until AD

\subsection{Comparison with other deforestation records}

The Aroi scenario cannot be extrapolated to the whole island, especially to coastal lowlands. In these lowlands, the situation was radically different. In addition to the core 
used in this study (ARO 08-02), the only well dated and fairly continuous sequence of the last millennia with a comparable resolution is RAR 08, from the lowland crater lake Rano Raraku (75 m elevation) (Fig. 1). This record shows that, at Raraku, deforestation began at $\sim 450 \mathrm{BC}$ and progressed in a gradual fashion for more than two millennia until its end at AD 1530 (Canellas-Bolt_a et al., 2013). As in Aroi, fires seem to have played a key role in this process. Human presencewas deduced from the occurrence of the weed V. litoralis, the first appearance of which coincided with the first fires and the onset of deforestation. Therefore, deforestation began 2000 years before and ended more than 100 years sooner in Raraku than in Aroi (Table 2). Regarding rates, deforestation was abrupt at Aroi ( $<100$ years) and gradual at Raraku, where it lasted more than 2000 years. Comparatively, deforestation proceeded $\sim 14$ times faster in Rano Aroi. Another lowland crater lake with palynological records is Rano Kao (110 m elevation) (Fig. 1), but the occurrence of frequent age inversions in its sediments has prevented the attainment of a sequence comparable to Aroi or Raraku for the last millennia (Horrocks et al., 2012). However, two deforestation events associated with increases in charcoal have been reported in the Kao record; the first (K1) between $\sim$ AD50 and $\sim$ AD100 and the second (K2) between AD 1350 and $\sim A D 1800$ (Butler and Flenley, 2010).

Because of dating issues, it is difficult to estimate the rates at which these events occurred, but K1 was likely more abrupt than K2 (Table 2). Remarkably, Rano Kao palm forests totally recovered after the $\mathrm{K} 1$ deforestation, which is the only case of forest regeneration after fire recorded so far on the island during the last millennia. A constant in all these deforestations is that they are accompanied by increases in charcoal, indicating fire exacerbation and, likely, human disturbance.

The comparison of the palynological records of Aroi, Raraku and Kao clearly documents the heterogeneous spatio-temporal deforestation patterns across Easter Island during the last two millennia. This suggests the occurrence of heterogeneous patterns of environmental change and/or local management by humans, which is in agreement with previous archaeological evidence (Stevenson and Haoa, 2008; Stevenson et al., 2015). It follows that paleoecological evidence from Easter Island should be analyzed under a mostly local perspective, likely restricted to the lake/mire catchment, and generalizations should be based on an overall consideration of all the available evidence over the whole island, rather than on the island-wide extrapolation of local observations (Rull et al., 2010). Local factors such as rainfall, elevation, area, latitude, age and isolation have been found to be relevant for understanding deforestation patterns across the whole assemblage of Pacific islands (Rolett and Diamond, 2004). Intra-island environmental and cultural variability, however, has not been sufficiently addressed but it may be relevant, even in an island as small as Easter Island, where the Aroi, Raraku and Kao catchments are remarkably heterogeneous in terms of elevation, size, topography, hydrology, microclimate, soils, vegetation and human activity (Stevenson and Haoa, 2008; Rull et al., 2010; Stevenson et al., 2015).

Accepting such heterogeneity would help reconcile accurate but apparently inconsistent empirical observations instead of having them used to erect contradictory hypotheses on the tempo and mode of Easter Island deforestation, particularly those which assume one single abrupt and island-wide deforestation event as a premise. 


\section{Acknowledgements}

This research was funded by the Spanish Ministry of Education and Science projects LAVOLTER (CGL2004-00683) and GEOBILA (CGL2007-60932/BTE). Fieldwork permits were facilitated by CONAF (Corporaci_on Nacional Forestal, Chile). 
Table 1. AMS radiocarbon dating: sample details, results and calibration. All samples consisted of pollen extracts. Calibration was performed with Calib 7.1 using the SHcal13 database.

\begin{tabular}{|l|l|r|r|r|}
\hline \multicolumn{1}{|c|}{ Sample } & \multicolumn{1}{|c|}{ Lab code } & Depth (cm) & ${ }^{\mathbf{1 4}} \mathbf{C}$ yr BP & Cal yr BP (2 $\sigma)$ \\
\hline ARO 08-02 02-25/26 & Poz-45907 & 76 & $190 \pm 30$ & $134-285$ \\
\hline ARO 08-02 02-35 & Poz-31998 & 85 & $270 \pm 30$ & $272-325$ \\
\hline ARO 08-02 03 9/10 & Beta-397173 & 110 & $760 \pm 30$ & $635-690$ \\
\hline ARO 08-02 03-25 & Poz-31999 & 125 & $1050 \pm 30$ & $898-963$ \\
\hline ARO 08-02 04-3/4 & Beta-397174 & 154 & $1730 \pm 30$ & $1533-1629$ \\
\hline ARO 08-02 04-25 & Poz-32000 & 175 & $2265 \pm 30$ & $2155-2329$ \\
\hline ARO 08-02 04-34 & Beta-197175 & 184 & $2550 \pm 30$ & $2463-2742$ \\
\hline
\end{tabular}

Table 2. Temporal differences between the deforestation events recorded at Easter Island using pollen analysis. Average deforestation rates have been estimated indirectly as the decline of palm pollen percentage per century $\left(\% \mathrm{C}^{-1}\right)$. Less reliable estimates are bracketed.

\begin{tabular}{|l|c|c|r|r|c|}
\hline $\begin{array}{c}\text { Deforestation } \\
\text { event }\end{array}$ & Onset & End & \multicolumn{1}{c|}{$\begin{array}{c}\text { Time } \\
\mathbf{( y )}\end{array}$} & $\begin{array}{c}\text { Rates (\%) } \\
\mathbf{1})\end{array}$ & References \\
\hline Rano Aroi & AD1520 & AD1620 & 100 & 73 & This paper \\
\hline Rano Raraku & 450BC & AD1530 & 1980 & 7 & 11 \\
\hline Rano Kao-K1 & (AD50) & (AD100) & $(50)$ & $(160)$ & 25 \\
\hline Rano Kao-K2 & (AD1350) & (AD1800) & $(450)$ & $(18)$ & 25 \\
\hline
\end{tabular}




\section{Figure captions}

1. Map of Easter Island showing the study site (Rano Aroi) and the other localities mentioned in the text (Rano Kao and Rano Raraku). Green areas indicate the Eucalyptus forests planted recently (Supplementary Information). The position of Easter Island on the world map is indicated by a red star. See SI Appendix, Fig. S1 for more details on Pacific geography.

2. Age-depth model using the best-fit option (linear interpolation). Two temporal scales (Cal years BP and AD/BC) are used to facilitate correlations. The solid line represents the mid-point age estimate (median) and the gray band is the $95 \%$ confidence interval for interpolated ages.

3. Synthetic diagram with the main palynological and geochemical parameters analyzed in the core ARO-08-02 from Rano Aroi. See SI Appendix, Figs. S2 and S3 for the full diagrams.

4. Correlations between the results obtained in this paper and the regional reconstructions for the Eastern Pacific during the last millennium. The well dated deforestation records that have been documented for Easter Island are also included. RWP - Roman Warm Period, DACP - Dark Ages Cold period, MWP - Medieval Warm Period, LIA - Little Ice Age. The boundary between the DACP and the MWP is indicated by a dashed line because its chronological uncertainty depends on the region. For example, in Europe, this boundary has been located at AD 950 while in the Pacific Basin, the beginning of the MWP has been dated to AD 750. EI - Easter Island, C Classic, PC - Preclassic. 


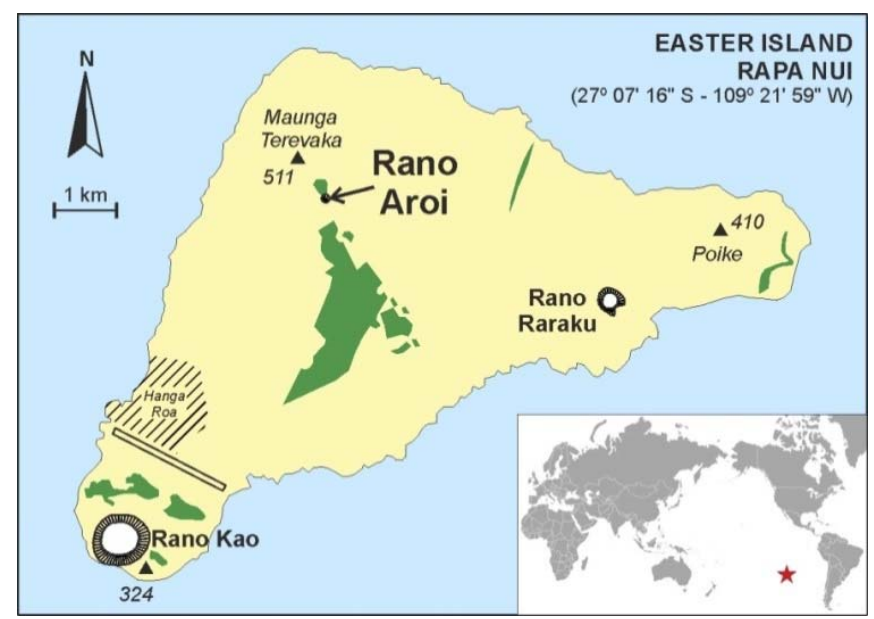

Figure 1

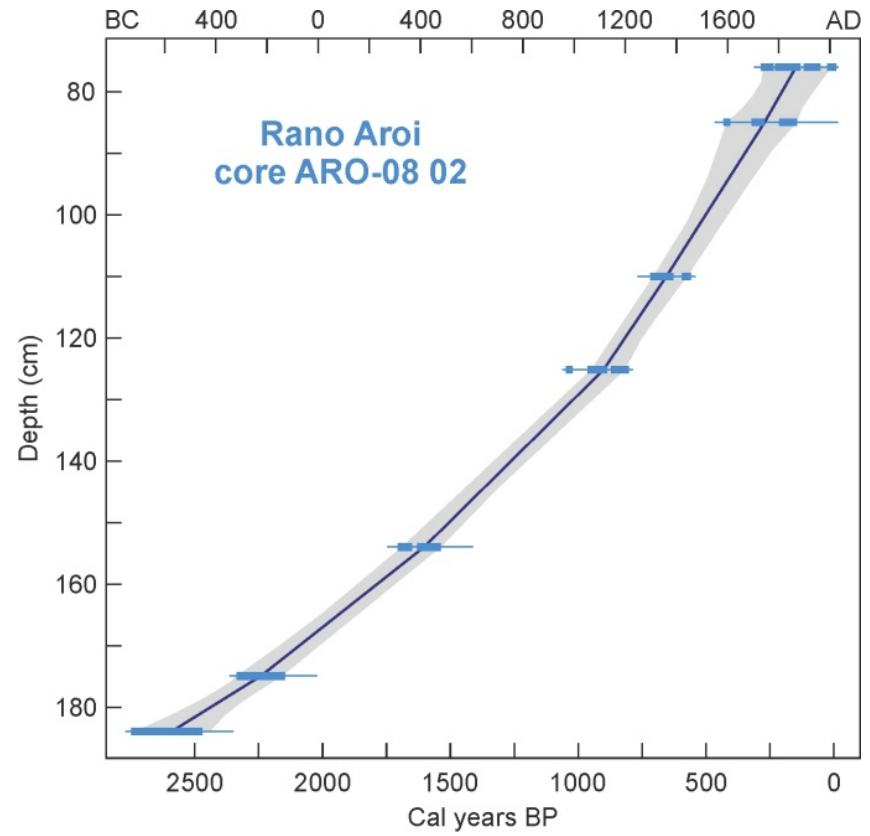

Figure 2 
Rano Aroi - core ARO-08 02

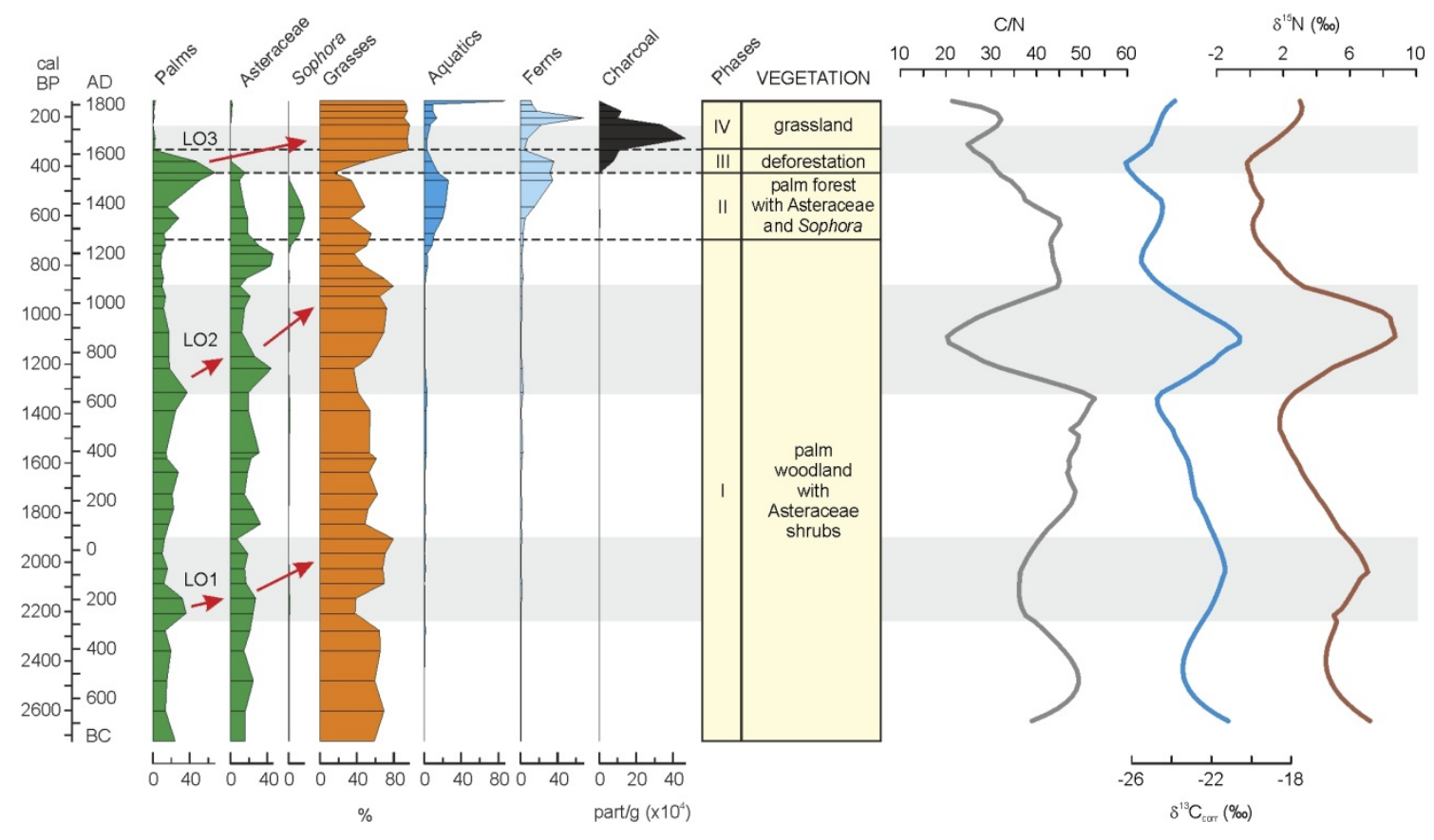

Figure 3

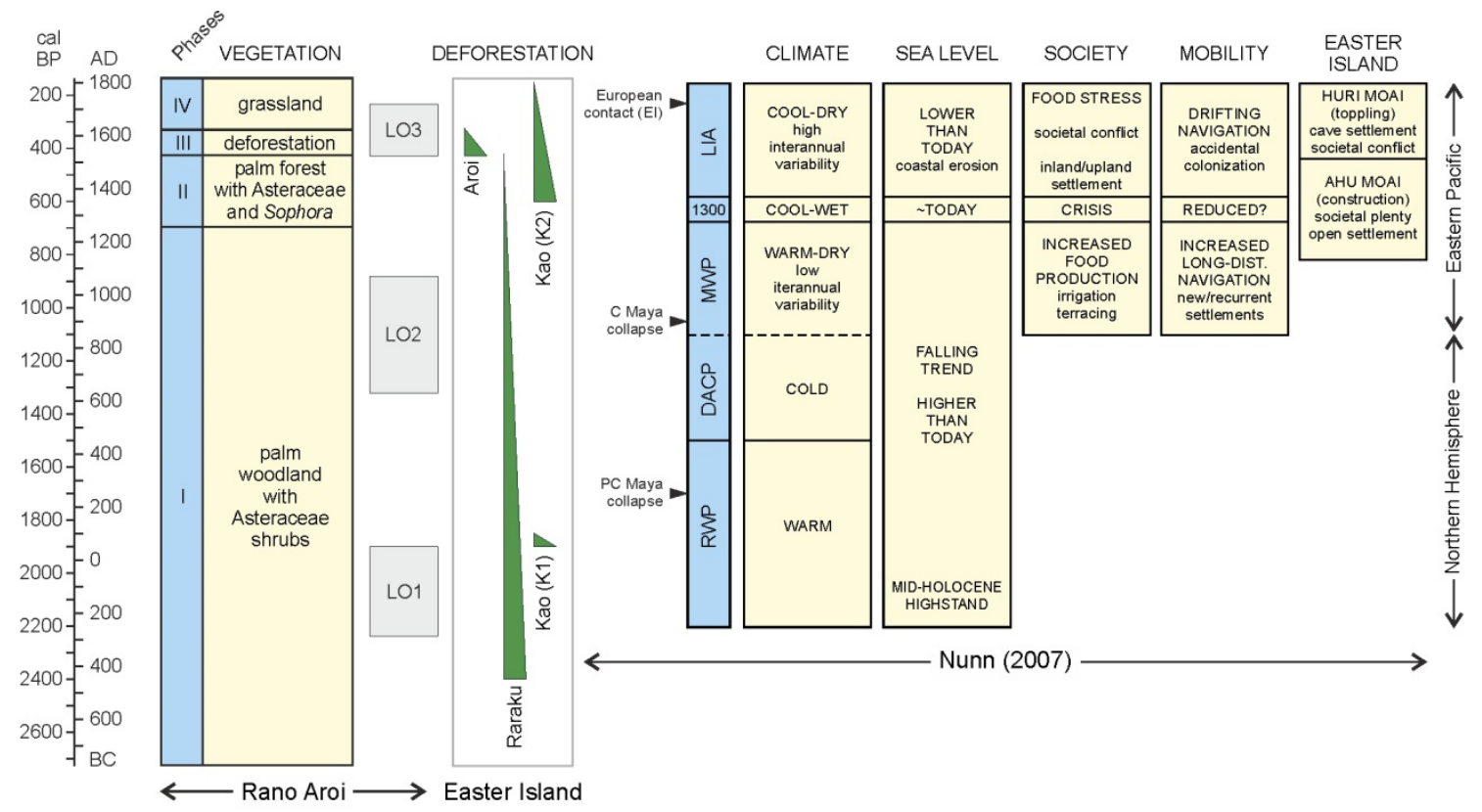

Figure 4 